\title{
Incidentalomas: managing risks
}

Incidentalomas: gerenciando riscos

\section{Rubens Chojniak ${ }^{1}$}

Incidentaloma is the medical term for incidentally found asymptomatic tumors. Such imaging findings have been increasingly frequent as the use of sectional imaging methods is disseminated ${ }^{(\mathbf{1})}$. Its incidence can hardly be established, but it is known that pulmonary nodules may be identified at up to $50 \%$ of chest computed tomography (CT) studies in smoking individuals and at up to $25 \%$ of studies of non-smokers ${ }^{(2,3)}$. At CT colonography, incidental findings are identified in up to $70 \%$ of patients and, at abdominal CT, renal and hepatic findings occur in about $15 \%$ of the individuals ${ }^{(3-}$ 5). Also, asymptomatic nodules are identified in up to $67 \%$ of individuals submitted to thyroid ultrasonography ${ }^{(3)}$.

Incidental imaging findings such as aortic aneurysms may be clinically significant, determining interventions that may change the natural course of the disease. However, most incidental findings constitute a form of overdiagnosis. Overdiagnosis is the diagnosis of a disease that never will cause symptoms or death of the patient, and is nowadays considered to be a public health problem $^{(3,6)}$. Usually, such diagnoses refer either to lesions with a benign nature or to least aggressive malignant lesions. Some cancers do not progress or are so indolent that will never produce symptoms in the patients who will die for other causes ${ }^{(6)}$.

The uncertainty and anxiety may lead to the automatic adoption of investigative measures with the objective of identifying the nature of any lesion that might even remotely represent a cancer $^{(7)}$. Such investigations, even imbued with the best intentions, may cause morbidity and even death in individuals who have harmless lesions $^{(7)}$.

A pediatric neurosurgeon has defined a new acronym to describe the risks associated with incidental imaging findings: VOMIT - victims of modern imaging technologies ${ }^{(\mathbf{8})}$.

In a letter to the Editor published in the Radiology journal, a radiologist, Dr. William J. Casarella, reported his personal experience with incidentalomas, starting with a virtual colonoscopy indicated in his routine check-up, that did not revealed any finding in his bowels. However, other findings triggered further investigations, percutaneous biopsy, videothoracoscopy, requiring some days in a hospital and a few weeks for him to get recovered. The experience has led Dr. Casarella to call his peers' attention to the potential risks caused by incidental findings ${ }^{(9)}$.

The management of incidental findings represents a clinical dilemma, but it is also influenced by other factors, such as cul-

1. Director, Imaging Department, A.C.Camargo Cancer Center, Professor at School of Medicine, Universidade Nove de Julho (Uninove), São Paulo, SP, Brazil. E-mail: chojniak@accamargo.org.br. tural issues, the people's belief that "you should better be safe than sorry". The reflexive adoption of such an assumption might lead to irremediable injuries caused by excessive investigation of indolent lesions $^{(7,10)}$. Another factor influencing the management of incidentalomas would be the defensive medicine practice. The fear of "missing" a cancer and to become legally liable may affect the physician's decisions, leading to a greater number of investigative procedures. The society seems to be more attentive to the shortage than to the excess of care and intervention ${ }^{(7,10)}$. Certainly, the role played by economic interests of medical equipment companies, hospitals and physicians, besides the health services remuneration model should not be underestimated ${ }^{(\mathbf{1 0})}$.

Then, what could we do in face of this scenario? Considering that incidentalomas are eminently radiological entities, the radiologist's opinion about an incidental imaging finding plays a critical role in the subsequent decision making process and may strongly interfere in such a scenario. Initially, as we have always done, we should know everything about this entity, namely, the frequency of occurrence of such findings, the spectrum of possible diagnoses, their respective rates of prevalence, radiological appearances and biological behavior ${ }^{(\mathbf{1 0 , 1 1})}$. More experienced radiologists or subspecialists dedicated to a specific field tend to indicate a lower number of additional examinations and tests to investigate incidental findings ${ }^{\text {(12-14) }}$.

Consistency is also a way to enhance the medical community's confidence in radiological results. The rates of recommendation for additional imaging studies are highly variable amongst the institutions and also amongst radiologists working in a same institution $^{\mathbf{( 1 2 - 1 5 )}}$. The adoption of investigation guidelines levels up the practice standards, offering greater confidence when the no further investigation is reccomended ${ }^{(\mathbf{1 2})}$. Several authors and medical societies pursue standardization initiatives in relation to the management of incidentalomas. One can mention the Fleischner Society's guidelines for asymptomatic pulmonary nodules detected at $\mathrm{CT}^{(\mathbf{1 6})}$, and the American College of Radiology (ACR) initiative that has organized a committee for incidental findings, and published management guidelines for the majority of incidental abdominal findings. Also, the ACR recommends that flowcharts are made widely available for radiologists during the preparations of their imaging reports ${ }^{(\mathbf{1 7})}$.

Finally, we could bring the "better safe than sorry" concept into question whenever there is a situation where the risk for missing a cancer is smaller than that caused by the investigation of ordinary benign and indolent lesions. 
Therefore, one should give an opinion including the risk/benefit concept, in order to avoid causing harm to those who are healthy.

\section{REFERENCES}

1. Brenner DJ, Hricak H. Radiology exposure from medical imaging: time to regu late? JAMA. 2010;304:208-9.

2. Wiener RS, Schwartz LM, Woloshin S, et al. Population-based risk for complications after transthoracic needle lung biopsy of a pulmonary nodule: an analysis of discharge records. Ann Intern Med. 2011;155:137-44.

3. Welch HG, Schwartz LM, Woloshin S. We stumble onto incidentalomas that might be cancer. In: Welch HG, Schwartz LM, Woloshin S, editors. Overdiagnosed: making people sick in the pursuit of health. Boston: Beacon Press; 2011. p. 90-101.

4. Lieberman DA. Clinical practice. Screening for colorectal cancer. N Engl J Med. 2009;361:1179-87.

5. Orme NM, Fletcher JG, Siddiki HA, et al. Incidental findings in imaging research: evaluating incidence, benefit, and burden. Arch Intern Med. 2010;170:152532.

6. Esserman $\sqcup$, Thompson IM Jr, Reid B. Overdiagnosis and overtreatment in cancer: an opportunity for improvement. JAMA. 2013;310:797-8.

7. Heath I. Role of fear in overdiagnosis and overtreatment - an essay by lona Heath. BMJ. 2014;349:g6123.

8. Hayward R. VOMIT (victims of modern imaging technology) - an acronym for our times. BMJ. 2003;326:1273.
9. Casarella WJ. A patient's viewpoint on a current controversy. Radiology. 2002; 224:927.

10. Moynihan R, Doust J, Henry D. Preventing overdiagnosis: how to stop harming the healthy. BMJ. 2012;344:e3502.

11. Brown SD. Professional norms regarding how radiologists handle incidental findings. J Am Coll Radiol. 2013;10:253-7.

12. Johnson PT, Horton KM, Megibow AJ, et al. Common incidental findings on MDCT: survey of radiologist recommendations for patient management. J Am Coll Radiol. 2011;8:762-7.

13. Sistrom CL, Dreyer KJ, Dang PP, et al. Recommendations for additional imaging in radiology reports: multifactorial analysis of 5.9 million examinations. Radiology. 2009;253:453-61.

14. Ip IK, Mortele KJ, Prevedello LM, et al. Focal cystic pancreatic lesions: assessing variation in radiologists' management recommendations. Radiology. 2011;259: 136-41.

15. Eisenberg RL, Bankier AA, Boiselle PM. Compliance with Fleischner Society guidelines for management of small lung nodules: a survey of 834 radiologists. Radiology. 2010;255:218-24.

16. MacMahon H, Austin JH, Gamsu G, et al. Guidelines for management of small pulmonary nodules detected on CT scans: a statement from the Fleischner Society. Radiology. 2005;237:395-400.

17. Berland LL, Silverman SG, Gore RM, et al. Managing incidental findings on abdominal CT: white paper of the ACR incidental findings committee. J Am Coll Radiol. 2010;7:754-73. 